\title{
Hysteroscopic versus Laparoscopic Tubal Occlusion in Hydrosalpinx Prior to ICSI
}

\author{
HISHAM NAGIB, M.D.; HESHAM SHALAN, M.D.; HAMED YOUSSEF, M.D. and \\ MOHAMED ALAA EL-DEEN MOSBAH, M.D.
}

The Department of Obstetrics and Gynaecology, Mansoura University Hospital, Mansoura Faculty of Medicine.

\begin{abstract}
Background: Studies carried out over the past years have suggested that hydrosalpinges reduce the pregnancy ratein IVF. The efficacy of hysteroscopic tubal electrocoagulation compared with laparoscopic tubaldisconnection for management of hydrosalpinx related infertility among patients undergoing ICSI.
\end{abstract}

Patients and Methods: A prospective study was conducted among patients who had unilateral or bilateral hydrosalpinges identified on hysterosalpingography and vaginal ultrasonography, and who were undergoingIVF at Mansoura University Hospital, gynecology outpatient clinic and fertility care clinic during period from January 2016 to January 2020.

Study Design: Non Randomized-controlled study.

Results: A total of 80 infertile women with documented hydrosalpinx and who will be subjected to IVF procedure were divided into 2 groups; (40) patients underwent hysteroscopic tubal electrocoagulation (group 1); the other (40) patients whom were submitted to laparoscopic disconnection of the tube (group 2). All patients who had contraindications for laparoscopy were scheduled for hysteroscopic tubal electrocoagulation so it was non randomized study. There was no statistically significant difference between both groups in age, BMI, and duration of infertility. For all patients, hysterosalpingography was performed 3 months after their procedure to evaluate proximal tubal occlusion. The procedure was successful in terms of tubal occlusion for 37 (93\%) of 40 hydrosalpinges in group 1, and $39(98 \%)$ of 40 hydrosalpinges in group $2(p=0.615)$. No intraoperative or postoperative complications were reported.

Conclusion: Hysteroscopic tubal electrocoagulation was found to be a successful treatment for hydrosalpinges before IVFwhen laparoscopy is contraindicated.

Key Words: Hydrosalpinx - Hysteroscopy - Electrocoagulation - In vitro fertilization - Laparoscopy - Tubal occlusion.

\section{Introduction}

HYDROSALPINX is an adnexal pathology, which can be easily recognized and confidently confirmed

Correspondence to: Dr. Hisham Nagib,

E-Mail :Hishamnagib@gmail.com using transvaginal ultrasound and HSG. The most consistent sonographic feature is a tubular structure with a well-defined echogenic wall and fold configurations protruding into the watery content [1]

Hydrosalpinx describes a spectrum of pathology of distal tubal occlusion. A strict definition is a collection of watery fluid in the fallopian tube, occurring as the end-stage of tubal infection. Chlamydia trachomatis is the most common pathogen to cause tubal infection. Numerous studies have reported on the poor outcome of IVF in patients with hydrosalpinx. The hydrosalpinx fluid has embryotoxic components and growth inhibiting factors. Another theory is the possibility of washout of embryos through leakage of fluid into the endometrial cavity. The hydrosalpinx fluid may also cause endometrial alterations hostile to embryo implantation and development [2] .

Different modalities have been suggested for the treatments of hydrosapinx with the aim of eliminating the hydrosalpingeal fluid before commencing IVF. Laparoscopic salpingectomy will be done to patients with ultrasound-visible hydrosalpinges but salpingectomy carries a potential risk of damaging the vascular and nervous supply to the ovary resulting in fewer oocytes being retrieved from the side of operation during IVF cycle in comparison with the side with intact adnexa. Many patients are often reluctant to agree to salpingectomy even if the pathology is clear, sometimes prefer to first undergo a salpingostomy if tubal mucosa is healthy as reconstructive tubal surgery [3-5].

Hysteroscopic tubal occlusion may be a solution for patients in whom laparoscopy is risky or contraindicated, e.g., in women who are obese, have severe cardiopulmonary dysfunctions or diaphragmatic hernia, or have previously undergone abdom- 
inal/pelvic surgery. Hysteroscopic tubal occlusion is an option when severe adhesions make salpingectomy technically difficult and there is a risk of damaging the ovary. The dilated tube can be left in place after occlusion of the proximal part [3]

Hysteroscopic approach to tubal occlusion offers a non-incisional alternative to laparoscopic surgery that eliminates the need for general anesthesia and that can be readily adapted to an outpatient or office setting. Benefits of this less invasive approach include reduced post procedure pain, allowing a patient to resume normal activities more quickly [6].

\section{Patients and Methods}

This prospective study was undertaken at Mansoura University Hospital, gynecology outpatient clinic and fertility care clinic during period from January 2016 to January 2020 and included 80 infertile women who were diagnosed having hydrosalpinx.

The study was approved by the Local Ethical Committee in Mansoura Faculty of Medicine. A verbal and written consent was obtained from each woman before the start of this study.

Tubal factor infertility was defined as the lack of tubal patency as judged by hysterosalpingography (HSG) and/or laparoscopy. A hydrosalpinx was defined as a distally occluded fallopian tube that was pathologically dilated on HSG or, when possible, on laparoscopy. Vaginal ultrasonography (mid-cycle) was performed for all participants; hydrosalpinx was diagnosed when an elongated tubular mass with echogenic wall and linear echoes in the lumen was observed.

A total of 80 infertile women with documented hydrosalpinx and who will be subjected to IVF procedure were divided into 2 groups:

- 1 st group included (40) patients whom were submitted to hysteroscopic electrocoagulation of the uterine ostium of the tube.

- 2 nd group included (40) patients whom were submitted to laparoscopic disconnection of the tube.

\section{Inclusion criteria:}

1- Age between 18 and 41 years.

2- Primary or secondary infertility.

3- Diagnosis of hydrosalpinx; diagnosed by HSG and TV U/S.

4- Necessity of an ICSI procedure.

\section{Exclusion criteria:}

1- Patients with uterine factor infertility such as fibroids (Type 0,1 or 2).

2- Patients with tubal obstruction.

3- Patients refuse the procedure.

4- Patient with uterine congenital anomalies.

\section{Methods:}

All eligible patients were submitted the following.

\section{History taking:}

Including duration and type of infertility (primary or secondary), sexual history, history suggestive of pelvic inflammatory disease, past history of pelvic surgery and history of chronic diseases.

\section{Clinical examination:}

General examination includes weight, height, BMI and thyroid examination. Abdominal examination includes scare of previous operations and abdominal masses. Local pelvic bimanual examination was done for uterus evaluation, tenderness or masses and speculum examination.

\section{Laboratory investigations:}

All patients had an infertility work-up including; FSH, LH, estradiol serum level, prolactin and TSH, husband seminal analysis, routine labs in the form of: Complete blood count, $\mathrm{Rh}$ typing, urine analysis, random blood glucose level, liver and kidney functions and coagulation profile.

\section{Pelvic sonography:}

Using a 7.5 MHz vaginal probe of Samsung Medison X5 ultrasound machine. The uterus was scanned in the sagittal plane for detection of any endometrial abnormality; visible hydrosalpinx in the form of elongated, diluted, tortuous tube containing fluid which is anechoic was recorded. In ultrasound image, hydrosalpinx looks as a tubular shape, echogenic wall, folded configurations and linear echos in the lumen of the fallopian tube.

Operation:

\section{Laparoscopic tubal disconnection:}

Laparoscopy was scheduled for patients with no contraindications to confirm the presence of the hydrosalpinx, and unilateral or bilateral tubal occlusion was performed when technically feasible by using bipolar coagulation and a proximal tubal cut. The contraindications for laparoscopy were mainly extensive abdominal or pelvic adhesions of various etiologies (e.g. previous surgery, pelvic inflammatory disease, and pelvic endometriosis) and morbid obesity. 


\section{Technique of Laparoscopic tubal disconnection:}

Under general anesthesia, using $5 \mathrm{~mm}$ ports for entry at the right and left lower quadrants, the affected fallopian tube(s) was identified. The tube was grasped and the monopolar diathermy was applied $2-3 \mathrm{~cm}$ from the cornua followed by cutting of the diathermized point using scissors.

\section{Hysteroscopic tubal electrocoagulation:}

All patients who had contraindications for laparoscopy were scheduled to undergo hysteroscopic tubal electrocoagulation under general anesthesia in the second week of their cycle. Unilateral or bilateral electrocoagulation of the corneal end of the tube and the surrounding part of the uterine horn was performed using aa 4-mm diameter hysteroscopy (Trokamed Endoscopy, Germany) with a bipotrode 5Fr reusable bipolar electrode (Tontarra, Germany).

\section{Technique of hysteroscopic tubal occlusion:}

Hysteroscopic fulguration of internal orifice of fallopian tubes at a hysteroscopic bipolar coagulation power of $40 \mathrm{w}$ within duration of 20 s was used, which leads to degeneration of internal orifice tissue of diseased tube by electric heat energy to form tissue scar so as to prevent hydrosalpinx fluid reflux to uterine cavity, helping embryo's development and implantation.

In hysteroscopic group, we use 4-mm diameter hysteroscopy with a bipotrode 5 Fr reusable bipolar electrode, which introduce through the cervix without any dilatation just use 2 tablet misoprostol $200 \mathrm{mg}$ before operation by 3 hours to soften the cervix. We insert bipolar electrode in operative channel before entrance to shorten the time of operation and decrease time of anesthesia. The uterine cavity was distended with saline solution with a continuous irrigating flow which is nontoxic, easily metabolized, and also less expensive than conventional hypotonic nonelectrolyte solutions. The saline is good conducted media for bipolar electrode.

During hysteroscopic procedure, fluid turbulence was observed as a sign of patent ostea then the bipolar electrode inserted at tubal ostea. Electric current used is coagulation at $40 \mathrm{w}$ for $10 \mathrm{sec}$ till stop fluid turbulence to ensure ostea closure by coagulation. Then the patient observed for $24 \mathrm{~h}$ for bleeding or considerable pain or fever. Discharge the patient on antibiotic and analgesic antiinflammatory.

\section{Follow-up:}

For all patients, genital infections were excluded. HSG had be done 2 menstrual cycles after the procedure to evaluate proximal tubal occlusion. Spasmofen ${ }^{\circledR}$ amp, Amriya Pharmaceutical Industries, Alexandria, Egypt was given IM one amp. $15 \mathrm{~min}$ before HSG to relieve tubal spasm if present to avoid false-veresult. By using $8 \mathrm{ml}$ water-soluble dye for HSG (OmnipaqueTM 350Mg Iodine/Ml Intravenous Solution, GE healthcare, United states) in follicular phase as standard dose in unilateral and bilateral hydrosalpinx.

\section{Statistical methods:}

Data were analyzed using Statistical Program for Social Science (SPSS) version 20.0. Quantitative data were expressed as mean \pm standard deviation (SD). Qualitative data were expressed as frequency and percentage.

- Probability ( $p$-value).

- $p$-value $\leq 0.05$ was considered significant.

- $p$-value $\leq 0.001$ was considered highly significant.

- $p$-value $>0.05$ was considered insignificant.

\section{Outcome measurements:}

The primary outcome was Evaluate two procedures, Laparoscopic tubal occlusion versus bipolar hysteroscopic tubal occlusion in-patient with hydrosalpinx.

\section{Results}

Table (1): Age, BMI in the studied groups.

\begin{tabular}{lccl}
\hline & $\begin{array}{c}\text { Hysteroscopy group } \\
(\mathrm{n}=40)\end{array}$ & $\begin{array}{c}\text { Laparoscopy group } \\
(\mathrm{n}=40)\end{array}$ & $p$ \\
\hline Age (years) & $28.95 \pm 5.188$ & $28.85 \pm 3.655$ & 0.921 \\
BMI & $30.95 \pm 3.515$ & $27.75 \pm 4.301$ & $\mathbf{< 0 . 0 0 1}$ \\
\hline
\end{tabular}

- Data is expressed as mean and standard deviation or as percentage and frequency.

$p$ is significant when $<0.05$.

In demographic features of the studied groups, both laparoscopic and hysteroscopic group were around the same infertility age range but in BMI aspect we founded that obese patient in the hysteroscopic group.

Table (2): Type and duration of infertility in the studied groups.

\begin{tabular}{llll}
\hline & $\begin{array}{c}\text { Hysteroscopy group } \\
(\mathrm{n}=40)\end{array}$ & $\begin{array}{c}\text { Laparoscopy group } \\
(\mathrm{n}=40)\end{array}$ & $p$ \\
\hline $\begin{array}{l}\text { Type of } \\
\text { infertility: }\end{array}$ & & & \\
$\quad$ Primary & $65.0 \%(26)$ & $40.0 \%(16)$ & $\mathbf{0 . 0 2 5}$ \\
$\quad$ Secondary & $35.0 \%(14)$ & $60.0 \%(24)$ & \\
Duration of & $6.78 \pm 3.475$ & $7.10 \pm 3.882$ & 0.694 \\
infertility & & & \\
\hline
\end{tabular}

- Data is expressed as mean and standard deviation or as percentage and frequency.

$p$ is significant when $<0.05$. 
The hysteroscopic group patients were primary infertility with average $6.7 \mathrm{y}$ duration of infertility and most laparoscopic group patients were secondary infertility with average 7.1y duration of infertility.

Table (3): Incidence and types of abdominal operation in the studied groups.

\begin{tabular}{lcll}
\hline & $\begin{array}{c}\text { Hysteroscopy } \\
\text { group } \\
(\mathrm{n}=40)\end{array}$ & $\begin{array}{c}\text { Laparoscopy } \\
\text { group } \\
(\mathrm{n}=40)\end{array}$ & $p$ \\
\hline $\begin{array}{l}\text { Previous abdominal } \\
\text { operations }\end{array}$ & $65.0 \%(26)$ & $67.5 \%(27)$ & 0.813 \\
Type of abdominal & & & \\
operations: & & & \\
$\quad$ CS & $20.0 \%(8)$ & $37.5 \%(15)$ & 0.084 \\
$\quad$ Laparoscopy & $12.5 \%(5)$ & $15.0 \%(6)$ & 0.745 \\
$\quad$ Ectopic & $7.5 \%(3)$ & $5.0 \%(2)$ & 0.644 \\
$\quad$ Laparotomy & $52.5 \%(21)$ & $10.0 \%(4)$ & $<\mathbf{0 . 0 0 1}$ \\
\hline
\end{tabular}

- Data is expressed as mean and standard deviation or as percentage and frequency.

$p$ is significant when $<0.05$.

As regard types of abdominal operations in the studied groups, we founded those 21 cases with previous laparotomies in hysteroscopic group and 4 cases only with previous laparotomies in laparoscopic group. No significant difference between both groups in CS, previous laparoscopy and ectopic surgery.

Table (4): Incidence of previous IVF cycles in the studied groups.

\begin{tabular}{lccc}
\hline & $\begin{array}{c}\text { Hysteroscopy } \\
\text { group } \\
(\mathrm{n}=40)\end{array}$ & $\begin{array}{c}\text { Laparoscopy } \\
\text { group } \\
(\mathrm{n}=40)\end{array}$ & $p$ \\
\hline Previous IVF cycles & $35.0 \%(14)$ & $35.0 \%(14)$ & 1 \\
\hline - Data is expressed as mean and standard deviation or as percentage \\
and frequency. \\
$p$ is significant when $<0.05$.
\end{tabular}

No significant difference between both groups in previous IVF cycles.

Table (5): Side of hydrosalpinx, method of diagnosis and degree of hydrosalpinx in the studied groups.

\begin{tabular}{llll}
\hline & $\begin{array}{c}\text { Hysteroscopy } \\
\text { group } \\
(\mathrm{n}=40)\end{array}$ & $\begin{array}{c}\text { Laparoscopy } \\
\text { group } \\
(\mathrm{n}=40)\end{array}$ & $p$ \\
\hline Side of hydrosalpinx: & & & \\
$\quad$ Bilateral & $22.5 \%(9)$ & $30.0 \%(12)$ & 0.379 \\
$\quad$ Right & $32.5 \%(13)$ & $40.0 \%(16)$ & \\
$\quad$ Left & $45.0 \%(18)$ & $30.0 \%(12)$ & \\
Diagnosis using TVS & $50.0 \%(20)$ & $35.0 \%(14)$ & 0.175 \\
Diagnosis using HSG & $100.0 \%(40)$ & $100.0 \%(40)$ & 1 \\
$\quad$ Degree of hydrosalpinx: & & & \\
$\quad$ Moderate & $50.0 \%(20)$ & $67.5 \%(27)$ & 0.112 \\
$\quad$ Severe & $50.0 \%(20)$ & $32.5 \%(13)$ & \\
\hline
\end{tabular}

- Data is expressed as mean and standard deviation or as percentage and frequency.

$p$ is significant when $<0.05$.
As regard side of hydrosalpinx, no significant difference in bilaterally or unilaterally in both groups. All patient were diagnosed using HSG in both group.

Table (6): Number of cases and tubal occlusion of unilateral and bilateral hydrosalpinx in post-operative HSG in the studied groups.

\begin{tabular}{llll}
\hline & $\begin{array}{c}\text { Hysteroscopy } \\
\text { group } \\
(\mathrm{n}=40)\end{array}$ & $\begin{array}{c}\text { Laparoscopy } \\
\text { group } \\
(\mathrm{n}=40)\end{array}$ & $p$ \\
\hline Unilateral hydrosalpinx: & & & \\
$\quad$ Number & 31 & 28 & 0.475 \\
$\quad$ Successful occlusion & 31 & 27 & \\
Occlusion failure & 0 & 1 & \\
Bilateral hydrosalpinx: & & & \\
$\quad$ Number & 9 & 12 & $\mathbf{0 . 0 3 1}$ \\
$\quad$ Successful occlusion & 6 & 12 & \\
$\quad$ Occlusion failure & 3 & 0 & \\
\hline
\end{tabular}

- Data is expressed as mean and standard deviation or as percentage and frequency.

$p$ is significant when $<0.05$.

Table (7): Total number of successful tubal occlusion of hydrosalpinx in post-operative HSG in the studied groups.

\begin{tabular}{lccc}
\hline & $\begin{array}{c}\text { Hysteroscopy } \\
\text { group } \\
(\mathrm{n}=40)\end{array}$ & $\begin{array}{c}\text { Laparoscopy } \\
\text { group } \\
(\mathrm{n}=40)\end{array}$ & $p$ \\
\hline Successful occlusion & 37 & 39 & 0.615 \\
Occlusion failure & 3 & 1 & \\
\hline
\end{tabular}

- Data is expressed as mean and standard deviation or as percentage and frequency.

$p$ is significant when $<0.05$.

As regard tubal occlusion in both studied group, we founded that 39 cases successful occlusion in laparoscopic group and 1 case failure of occlusion. In hysteroscopic group we founded that 37 cases successful occlusion but 3 cases failure of occlusion because those 3 cases were bilateral hydrosalpinx.

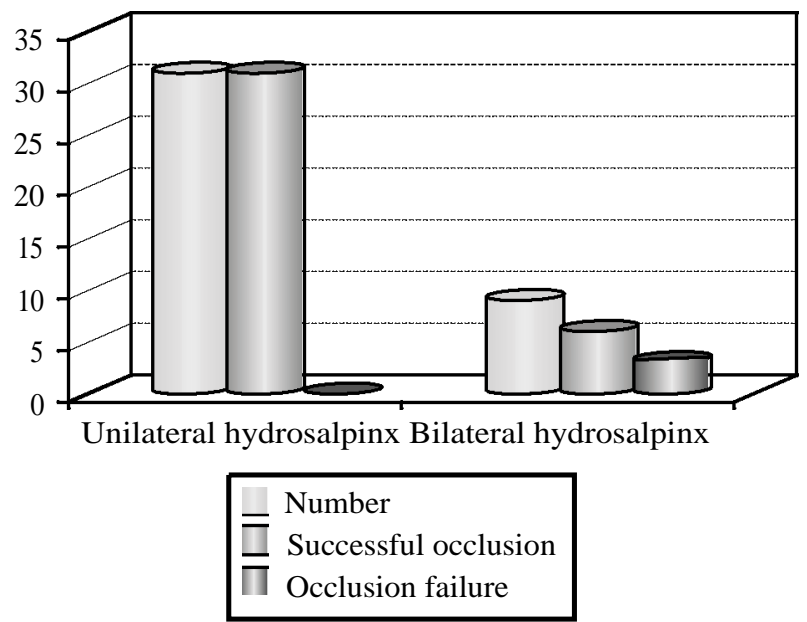

Fig. (1): Tubal occlusion of unilateral and bilateral hydrosalpinx in hysteroscopic group with occlusion failure in 3 cases of bilateral hydrosalpinx. 


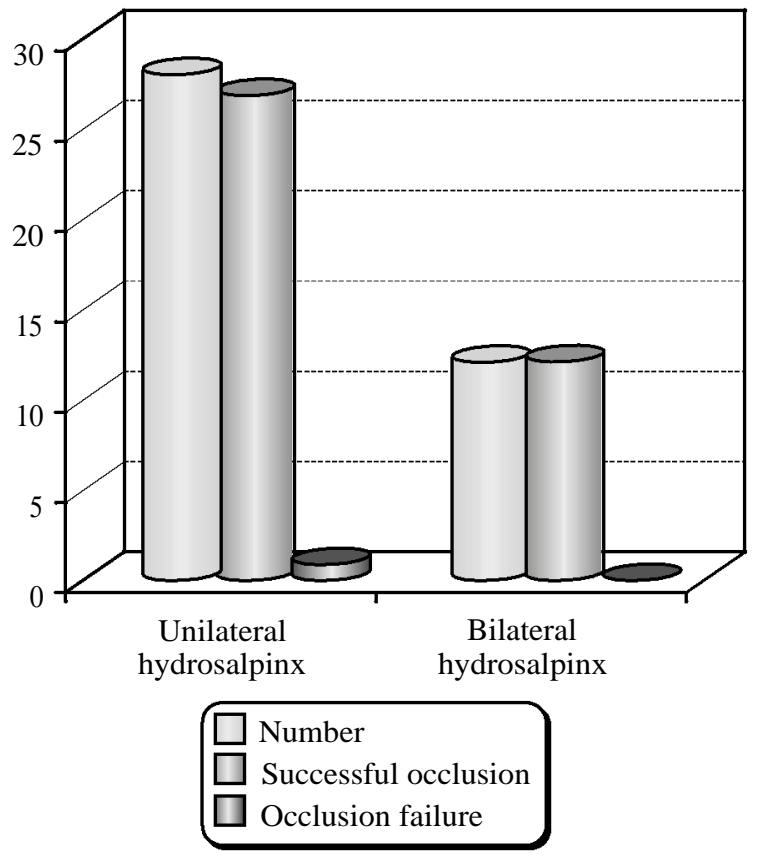

Fig. (2): Tubal occlusion of unilateral and bilateral hydrosalpinx in laparoscopic group with occlusion failure in 1 case of unilateral hydrosalpinx.

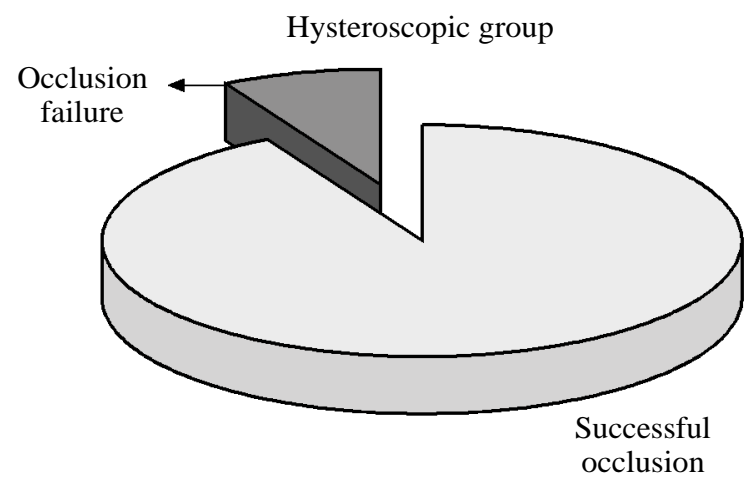

Fig. (3): The success of tubal occlusion of hydrosalpinx in post-operative HSG in hysteroscopic group 93\% with $8 \%$ occlusion failure.

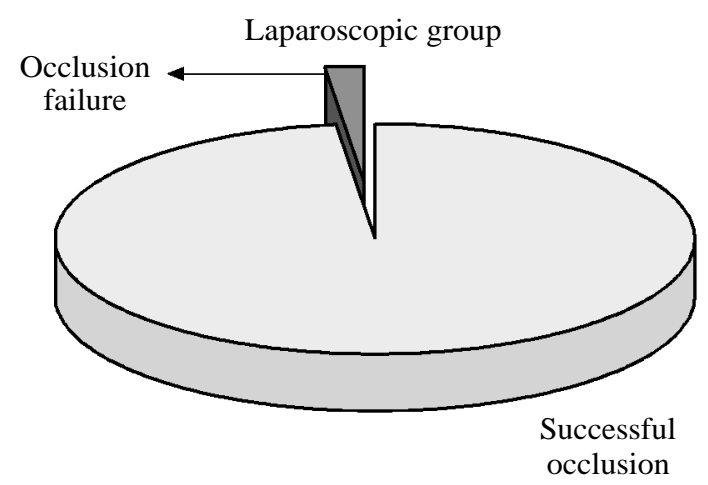

Fig. (4): The success of tubal occlusion of hydrosalpinx in post-operative HSG in laparoscopic group $98 \%$ with $2 \%$ occlusion failure.
Table (8): Operation time and type of anesthesia in the studied groups.

\begin{tabular}{llll}
\hline & $\begin{array}{c}\text { Hysteroscopy } \\
\text { group } \\
(\mathrm{n}=40)\end{array}$ & $\begin{array}{c}\text { Laparoscopy } \\
\text { group } \\
(\mathrm{n}=40)\end{array}$ & $p$ \\
\hline $\begin{array}{l}\text { Operative time } \\
\text { (minutes) }\end{array}$ & $8.18 \pm 1.999$ & $32.13 \pm 7.556$ & $<\mathbf{0 . 0 0 1}$ \\
$\begin{array}{c}\text { Type of anesthesia: } \\
\text { Intubation }\end{array}$ & $0.0 \%(0)$ & $100.0 \%(40)$ & $<\mathbf{0 . 0 0 1}$ \\
$\quad$ Laryngeal mask & $100.0 \%(40)$ & $0.0 \%(0)$ & \\
\hline
\end{tabular}

- Data is expressed as mean and standard deviation or as percentage and frequency.

$p$ is significant when $<0.05$

As regard operative time in both studied groups, hysteroscopic group with average time $8 \mathrm{~min}$ in comparing with laparoscopic group average time was $32 \mathrm{~min}$ because the operative anesthesia was sedative laryngeal mask in hysteroscopic group and general anesthesia intubation in laparoscopic group.

Table (9): Hospital stay and analgesic duration in the studied groups.

\begin{tabular}{lccc}
\hline & $\begin{array}{c}\text { Hysteroscopy } \\
\text { group } \\
(\mathrm{n}=40)\end{array}$ & $\begin{array}{c}\text { Laparoscopy } \\
\text { group } \\
(\mathrm{n}=40)\end{array}$ & $p$ \\
\hline $\begin{array}{l}\text { Hospital stay (hours) } \\
\text { Analgesic duration } \\
\text { (days) }\end{array}$ & $\begin{array}{l}4.53 \pm 1.176 \\
1.55 \pm 0.597\end{array}$ & $16.80 \pm 5.9541 .198$ & $\mathbf{< 0 . 0 0 1}$ \\
\hline $\begin{array}{l}\text { - Data is expressed as mean and standard deviation or as percentage } \\
\text { and frequency. }\end{array}$ \\
$p$ is significant when $<0.05$.
\end{tabular}

According to hospital stay after both procedures, we founded short hospital stay around 4 hours in hysteroscopic group in compare with 17 hours hospital stay in laparoscopic group also need of post-operative analgesic less number of ampoules in hysteroscopic group than laparoscopic one.

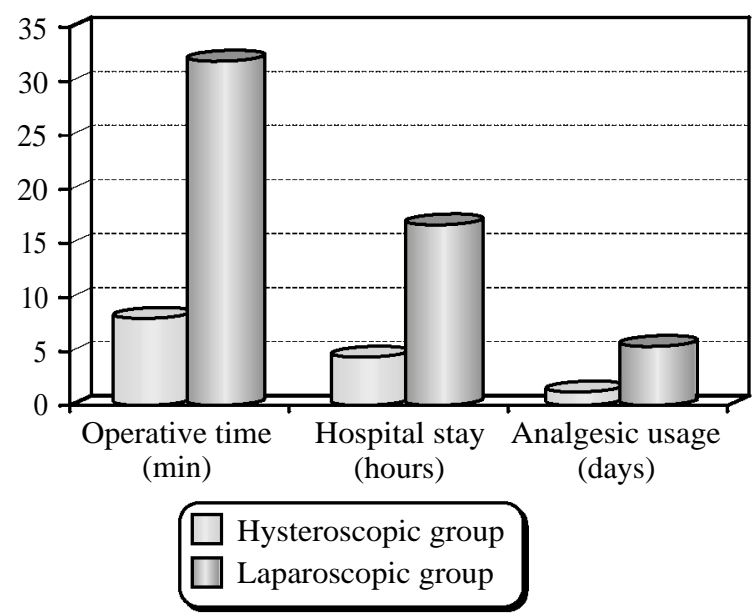

Fig. (5): Time of operation, hospital stay and analgesic duration in the studied groups. 


\section{Discussion}

In present study, we divided 80 patients in two groups. Hysteroscopic group which include mainly patient contraindicated to laparoscopy as patient with midline laparotomy, evidence of extensive adhesion, sever endometriosis, previous failed laparoscopy and medically contraindicated to general anesthesia and peritoneal insufflation in laparoscopy. Laparoscopic group included the other 40 patient.

The present prospective clinical trial has investigated the success rate of hysteroscopic tubal electrocoagulation for the treatment of hydrosalpinx related infertility among women undergoing IVF procedures. The presence of proximal tubal occlusion on post-procedure HSG was used as the main outcome measure; IVF outcome was not considered because it can be affected by many other prognostic factors. To minimize the false-positive results of HSG in the differentiation between true tubal occlusion and tubal spasm, water-soluble dye and antispasmodics were used in pre- and postprocedure HSGs. In addition, the findings from pre-procedure HSG were used as a control.

Sufficient evidence shows the negative effect of hydrosalpinx fluid in the uterine cavity on female fecundity, in addition to the significant improvement in fertility after occlusion of the hydrosalpinx. Although laparoscopic procedures (salpingectomy or proximal tubal disconnection) have proven efficacy, the cumulative risks for patients intending to undergo IVF treatment are a concern. Hysteroscopic procedures (either an Essure insert or electrocoagulation) are regarded as simpler and safer.

When we started this study, we began at first with10 cases as sample size. We faced two problem, firstly type of study if randomized so many patient will settled in laparoscopic group may be clinically unfit for general anesthesia and may be unfit for laparoscopy surgery itself due to severe abdominal adhesions as a result of many laparotomies that increase incidence of internal organ injuries so we decided to make study non randomized.

Second problem we founded was amount of HSG dye had been used to assess tubal patency after operation, we used $20 \mathrm{ml}$ dye as in usual HSG but found that this amount removed fibrosed coagulum which formed after hysteroscopic electrocoagulation and reopen the hydrosalpinx tube after closure so we decided to standardization the amount of dye around $8 \mathrm{ml}$ to asses closure of the tube.
According to demographic features of the studied groups, both laparoscopic and hysteroscopic group were around the same infertility age range but in BMI aspect we founded that obese and morbid obese patient in hysteroscopic group to decrease risk of general anesthesia in obese if we done laparoscopy.

According to type of infertility, most hysteroscopic group patients were primary infertility with average $6.7 y$ duration of infertility and most laparoscopic group patients were secondary infertility to manage other causes of infertility as mild and moderate degree of endometriosis and simple adhesiolysis with average 7.1y duration of infertility.

According to types of abdominal operations in the studied groups, we founded those 21 cases with previous laparotomies in hysteroscopic group and 4 cases only with previous laparotomies in laparoscopic group. As regard previous IVF cycles in both group were no significant difference.

As regard tubal occlusion in both studied group, we founded that 39 cases successful occlusion in laparoscopic group and 1 case failure of occlusion due to sever pelvic adhesions in this case that laparoscopic salpingectomy was very difficult to had done without injury of surrounding adherent structure so we just done laparoscopic bipolar electrocoagulation of hydrosalpinx side. In hysteroscopic group we founded that 37 cases successful occlusion but 3 cases were occlusion failure because that 3 cases were bilateral hydrosalpinx with small sized uterus and with follow-up 8ml HSG dye injection we founded that amount made too much pressure on both fiberosed coagulated sides which lead to partial leakage in one side so recorded as occlusion failure.

As regard operative time in both studied groups, undoubtedly hysteroscopic group win that average time $8 \mathrm{~min}$ in comparing with laparoscopic group average time was $32 \mathrm{~min}$ so the operative anesthesia was sedative laryngeal mask in hysteroscopic group and general anesthesia intubation in laparoscopic group. Again hysteroscopic group win in less risk of anesthesia.

According to hospital stay after both procedures, we founded short hospital stay around 4 hours in hysteroscopic group in compare with 17 hours hospital stay in laparoscopic group also need of post-operative analgesic less number of ampoules in hysteroscopic group than laparoscopic one.

A prospective clinical trial by El-Mazny et al., had investigated the success rate of hysteroscopic 
tubal electrocoagulation for the treatment of hydrosalpinx related infertility among a relatively large number of patients with laparoscopic contraindications undergoing IVF, Overall, the procedure was successful in terms of tubal occlusion for 25 (93\%) of 27 hydrosalpinges in hysteroscopic group and 78 (96\%) of 81 hydrosalpinges in laparoscopic group, with no significant difference between the two groups. These results are close to our study results and that may be due to some common points that were used in both studies, as all the hysteroscopic procedures in both studies were performed in the early follicular phase and the instruments used were close to each other, as they used in this previous study the electrocoagulation roller ball as we used in our study.

Hysteroscopic tubal electrocoagulation might be a possible alternative to the laparoscopic procedure for hydrosalpinx treatment before IVF. However, hysteroscopic surgery is associated with both the potential risk of electrosurgical injury and complications of distending media. In the present study, electrosurgical injury was avoided by proper insulation and by using the lowest possible power setting, whereas complications of distending media were prevented by proper monitoring of fluid input and output, and by keeping the uterine cavity distention pressure below the mean arterial pressure to avoid fluid and electrolyte disturbances. No intraoperative or postoperative complications were reported in the present study.

\section{Conclusion:}

The evaluation of two procedures, laparoscopic tubal occlusion versus bipolar hysteroscopic tubal occlusion in-patient with hydrosalpinx found that both laparoscopy and hysteroscopy are effective methods for tubal occlusion in case of hydrosalpinx; however the hysteroscopy has the advantages of being less invasive approach, non-incisional alternative to laparoscopy when laparoscopic surgery contraindicated, also eliminates the need for general anesthesia, less operative time, less post procedure pain and more quickly resume normal activities.

\section{Recommendations:}

- Large number of cases should be including in future studies.

- Being the clinical study randomized to be more strong study.

- Long term follow-up for cases as pregnancy rate should be included.

- Handling the amount of dye used in follow-up HSG according to uni- or bilateral hydrosalpinx and size of uterine cavity.

Limitations in this study:

- Small number of cases included in this study.

- Being the clinical study non-randomized is a weak point in this study.

- Absences of long term follow-up for cases.

\section{Acknowledgment:}

We acknowledge that all authors have contributed significantly, and that all authors agree with the content of the manuscript.

\section{References}

1- STRANDELL A.: Management of hydrosalpinx. Textbook of Assisted Reproductive Techniques, 308, 2012.

2- ALETEBI F.: Hysteroscopy in women with implantation failures after in vitro fertilization: Findings and effect on subsequent pregnancy rates. Middle East Fertility Society Journal, 15 (4): 288-291, 2010.

3- JOHNSON N.P., VAN VOORST S., SOWTER M.C., STRANDELL A. and MOL B.W.: Surgical treatment for tubal disease in women due to undergo in vitro fertilization. Cochrane Database. Syst. Rev., 1, CD002125, 2010.

4- WATRELOT A. and CHAUVIN G.: Current practice in tubal surgery and adhesion management: a review. Reproductive BioMedicine Online 2011. 23: 53- 62

5- CAROL COUGHLAN and TC LI: An update on surgical management of tubal disease and infertility. Obstetrics, Gynaecology and Reproductive Medicine, 21 (10): 277, 2011.

6- PASIC R.P. and LEVINE R.L.: A Practical Manual of Hysteroscopy and Endometrial Ablation Techniques: A Clinical Cookbook. CRC Press, 2004. 


\section{تقييم فاعلية غلق قناة فالوب بالمنظار الرحمى

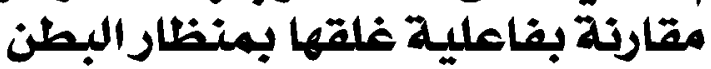

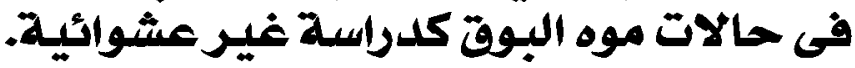 فى مستشفى جامعة المنتصورة}

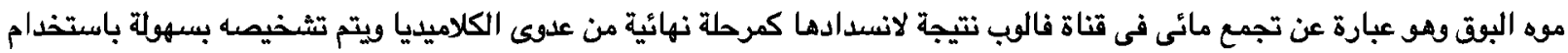

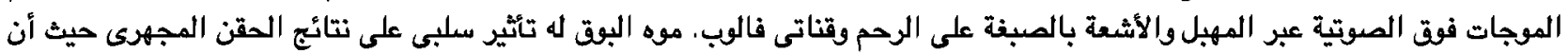

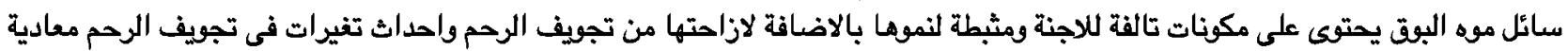
الزنرع الاجنة.

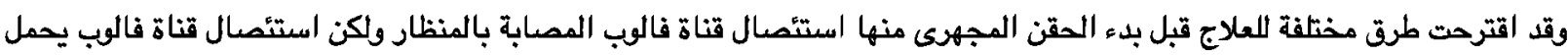

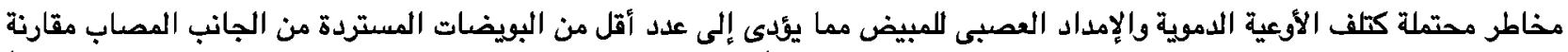

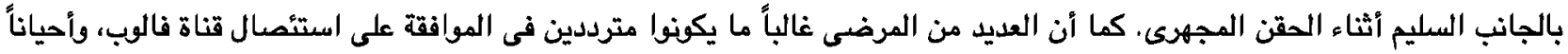

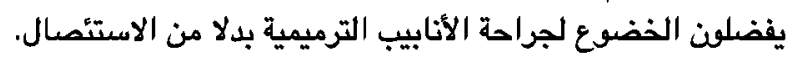

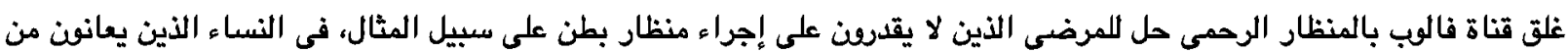

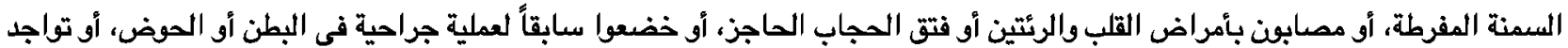
التصاقات شديدة تمنع استئصال قناة فالوبي.

غلق قناة فالوب بالمنظار الرحمى يقدم بديلاً لمنظار البطن الذى يلفى الحاجة اللتذير العام والتى يمكن اجرائه بسههولة فى العيادات

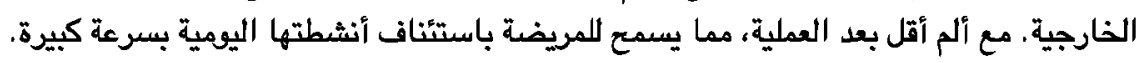

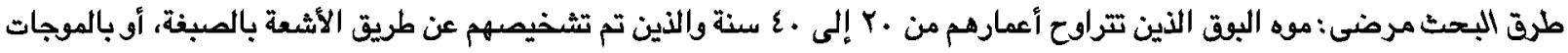

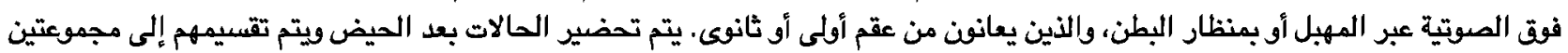

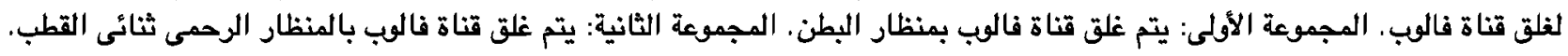

ويتم متابعة جميع المرضى مدة دورتين شهريتين.

الهدف من الدراسة: تقيم فاعلية غلق قناة فالوب بالمنظار الرحمى مقارنة بفاعلية غلقها بمنظار البطن فى حالات موه البوق كدراسة غير

عشوائية، فى مستشفى جامعة المنصورة فاعلية

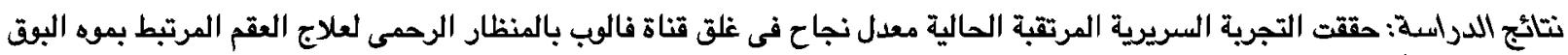

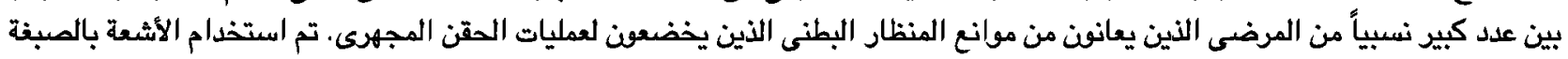

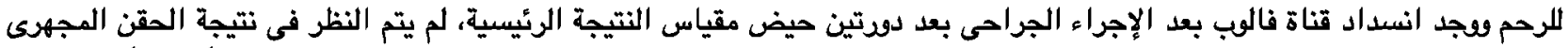

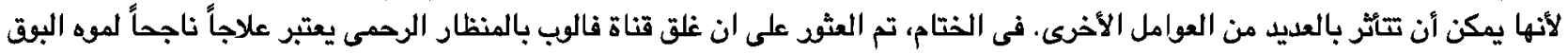

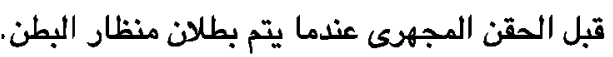

